\title{
Finite element model calculations of temperature profiles in Nd:YAG laser annealed GaAs/AlGaAs quantum well microstructures
}

\author{
Radoslaw STANOWSKI, Oleksandr VOZNYY and Jan J. DUBOWSKI \\ Department of Electrical and Computer Engineering \\ Research Center for Nanofabrication and Nanocharacterization \\ Université de Sherbrooke, Sherbrooke, Québec J1K 2R1, Canada \\ E-mail: jan.j.dubowski@usherbrooke.ca
}

\begin{abstract}
Infra-red (IR) laser induced selective-area quantum well intermixing (QWI) has the potential to yield multi-bandgap quantum well wafers suitable for the fabrication of monolithically integrated photonic devices. Quantitative description of the IR laser-QWI process requires knowledge of temporal and spatial temperature profiles induced by the laser. This requires solving a 3-dimensional heat diffusion equation, which takes into account laser parameters and the irradiation conditions. We report the results of modeling temperature profiles in semiconductor wafers irradiated with a stationary $\mathrm{CW}$ $\mathrm{Nd}$ :YAG laser beam $(\lambda=1064 \mathrm{~nm})$. The calculations were carried out using a finite element model and taking into account convection, background heating, as well as temperature dependent both heat conductivity and optical absorption. A reasonable agreement has been observed between calculated and measured temporal dependencies of the laser induced temperatures. Our calculations indicate that lines of the GaAs/AlGaAs QWI material could be 50\% narrower than the diameter of the laser writing spot if the background temperature of the wafer is increased to about $700{ }^{\circ} \mathrm{C}$.
\end{abstract}

DOI: 10.2961/jlmn.2006.01.0004

Keywords: GaAs/AlGaAs quantum well microstructures, quantum well intermixing, laser annealing, finite element model calculations

\section{Introduction}

Manufacturing of monolithically integrated photonic circuits requires III-V semiconductor wafers with zones of different bandgap materials. In recent years, quantum well intermixing (QWI) has become one of the most investigated methods for selective-area bandgap shifting $[1,2]$. Various techniques of QWI have been investigated based on spatially selective impurity-induced diffusion [3-5], ion implantation [6] and impurity free vacancy diffusion [7]. Additionally, transient melting of multiple layers by pulsed laser irradiation [8] has proven to be effective for QWI. Laser annealing has also been used to introduce encapsulant $\mathrm{Si}$ into the epitaxial layers as a source for impurity-induced disordering [9]. The maximum lateral resolution of QWI achieved with pulsed $\mathrm{Nd}$ :YAG laser $(\lambda=1064 \mathrm{~nm})$ irradiating a dedicated mask has been reported to be about $25 \mu \mathrm{m}$ [10] and $3 \mu \mathrm{m}$ [11]. These techniques, although clearly effective, seem to be complicated by a number of additional processes, such as the introduction of impurities or various masking steps, and they can suffer from the increased free-carrier population as well as from implantation-induced damage. Infra-red laser rapid thermal annealing (LRTA) is a promising QWI technique because it allows for the fabrication of a selective-area bandgap shifted material, without mask and potentially with a high lateral resolution. Quantitative description of LRTA-based QWI requires detailed knowledge of both temporal and spatial temperature profiles induced in a quantum well (QW) wafer. The process has to take into account the laser's wavelength and composition and geometry of the irradiated QWI wafer as well as the conditions under which the irradiation takes place, such as the wafer's surface reflectivity, the pressure and temperature of surrounding gas, laser power density, speed of laser writing beam, etc. In this paper, we employed a phenomenological approach for the calculation of heat transfer by using the finite element method (FEM). We calculated the temporal and both lateral and in-depth temperature profiles induced by a CW Nd:YAG laser $(\lambda=1064 \mathrm{~nm})$ in GaAs and Si wafers. The results concern the irradiation with a stationary laser beam. One of the goals of this approach was to simulate conditions leading to the ultimate lateral resolution of the LRTA QWI process. Preliminary verification of the model was carried out by describing the experimental data of transient temperature profiles observed in both $\mathrm{GaAs}$ and $\mathrm{Si}$ [12] wafers. We argue that the results are relevant for the GaAs/AlGaAs QW microstructures.

\section{Temperature calculations}

We carried out the FEM calculations to solve 3-dimensional partial differential equations (PDE) using commercial FEMLAB software. The FEM approach takes advantage of the finite element discretization of the calculated model's geometry into mesh elements. The properties of adjacent elements in the nodes of the generated net are shared during progressive iteration steps, so the energy flux phenomena could be calculated, e.g., for diffusion or heat transfer [13]. The FEM method allows generating mesh elements of various sizes and shapes, depending on the calculated physical process. The size of mesh elements is a critical factor for accuracy of the calculated results, but also it influences the total time of calculations. 
The heat balance according to the heat transfer PDE equation for every differential element is based on the relation [14]:

$\underline{\text { Heat in }}-\underline{\text { Heat out }}=\underline{\text { Heat accumulated }}+\underline{\text { Heat generated, }}$

which for the case investigated in this paper could be expressed by the following equation:

$$
\mathrm{Q}-\nabla(\mathrm{k} \nabla \mathrm{T})=\rho \mathrm{C}_{\mathrm{p}}(\partial \mathrm{T} / \partial \mathrm{t})
$$

where

$$
\mathrm{Q}=(1-\mathrm{R}) \cdot \mathrm{I} \cdot \mathrm{A} \cdot \alpha \cdot \exp (-\alpha \cdot \mathrm{z})\left[\mathrm{W} / \mathrm{m}^{3}\right]
$$

and

$\mathrm{R}$ - Optical reflectivity

I - Laser beam intensity parameter $\left[\mathrm{W} / \mathrm{m}^{2}\right]$,

A - Laserbeam shape function,

$\alpha$ - Optical absorption $\left[\mathrm{m}^{-1}\right]$,

$\mathrm{k}$ - Thermal conductivity $[\mathrm{W} /(\mathrm{m} \cdot \mathrm{K})]$

$\mathrm{T}$ - Wafer temperature [K]

$\rho-$ Density $\left[\mathrm{kg} / \mathrm{m}^{3}\right]$

$\mathrm{C}_{\mathrm{p}}-$ Specific heat $[\mathrm{J} /(\mathrm{kg} \cdot \mathrm{K})]$

$\mathrm{z}-$ Depth [m]

Due to the finite optical absorption of the Nd:YAG laser beam the heat is generated inside the irradiated wafer. The equation for $\mathrm{Q}$, which describes the heat source, takes into account optical reflectivity, laser beam power density, beam shape and optical absorption of the irradiated wafer. The boundary equation is given by:

$$
\mathrm{q}_{0}-\mathrm{h}\left(\mathrm{T}_{\mathrm{inf}}-\mathrm{T}\right)+\operatorname{Const}\left(\mathrm{T}_{\mathrm{amb}}^{4}-\mathrm{T}^{4}\right)=\mathrm{k} \nabla \mathrm{T},
$$

where:

$\mathrm{q}_{0}-$ Inward flux $\left[\mathrm{W} / \mathrm{m}^{2}\right]$

$\mathrm{h}-$ Convective heat transfer coefficient $\left[\mathrm{W} / \mathrm{m}^{2} \cdot \mathrm{K}\right]$

$\mathrm{T}_{\mathrm{inf}}-$ Temperature close to the surface(heat convection) $[\mathrm{K}]$

$\mathrm{T}_{\mathrm{amb}}-$ Ambient temperature (heat radiation) $[\mathrm{K}]$

Const - Emissivity-sigma (Stefan Boltzman's heat radiation constant) $\left[\mathrm{W} / \mathrm{m}^{2} \cdot \mathrm{K}^{4}\right]$

To simplify the calculations, we assumed that the irradiated samples are of circular shape. This allowed us to use a 2D model employing circular axial symmetry. Calculations were carried out to determine the temporal temperature behavior in the middle of the laser irradiated spot as well as for both lateral and in-depth temperature profiles. The irradiating laser spot was situated in the center axis of the model's geometry. For non-circular wafers, the modeled surface area was adjusted to make it equal to the surface area of the wafer used in the experiment. In the case of a $14 \mathrm{~mm}$ × $6 \mathrm{~mm}$ sample, this corresponds to about a 9-mm diameter wafer. The calculations have been carried out for wafers irradiated with laser spots of 3, 0.7 and $0.1 \mathrm{~mm}$ in diameter. The material parameters used in the calculations are summarized in Table 1 . The calculations for a GaAs wafer irradiated with a 3-mm diameter spot were used to simulate temporal temperature profiles that were measured in the GaAs/AlGaAs QW microstructure. Figures 1 and 2 show the calculated transient temperatures in the middle of the 3-mm diameter laser spot irradiating the GaAs wafer with a $1 \mathrm{~W} / \mathrm{mm}^{2}$ power. Fig. 1 shows calculations carried out for different thermal conductivity
Table 1 Parameters of GaAs used in calculations of transient and spatial temperature profiles.

\begin{tabular}{c|c|c|c|}
\hline $\begin{array}{c}\text { Thermal } \\
\text { conductivity } \\
{[\mathrm{W} / \mathrm{m} \cdot \mathrm{K}]}\end{array}$ & $\begin{array}{c}\text { Specific } \\
\text { heat } \\
{[\mathrm{J} / \mathrm{kg} \cdot \mathrm{K}]}\end{array}$ & $\begin{array}{c}\text { Density } \\
{\left[\mathrm{kg} / \mathrm{m}^{3}\right]} \\
\text { Ref. } \\
\text { Ref. }[15,16]\end{array}$ & $\begin{array}{c}\text { Optical absorption } \\
{\left[\mathrm{cm}^{-1}\right]}\end{array}$ \\
$\begin{array}{c}\text { Ref. }[15,16] \\
\text { 56@300K }\end{array}$ & & & $\begin{array}{c}-7492.5+24.985 \cdot \mathrm{T}, \text { for } \\
\text { Ref. }[15,16,17]\end{array}$ \\
or & 325 & 5317 & $300 \mathrm{~K}<\mathrm{T}<1100 \mathrm{~K}$ \\
$16280 / \mathrm{T}$ & & & 20000, for $\mathrm{T}>1100 \mathrm{~K}$ \\
\hline
\end{tabular}

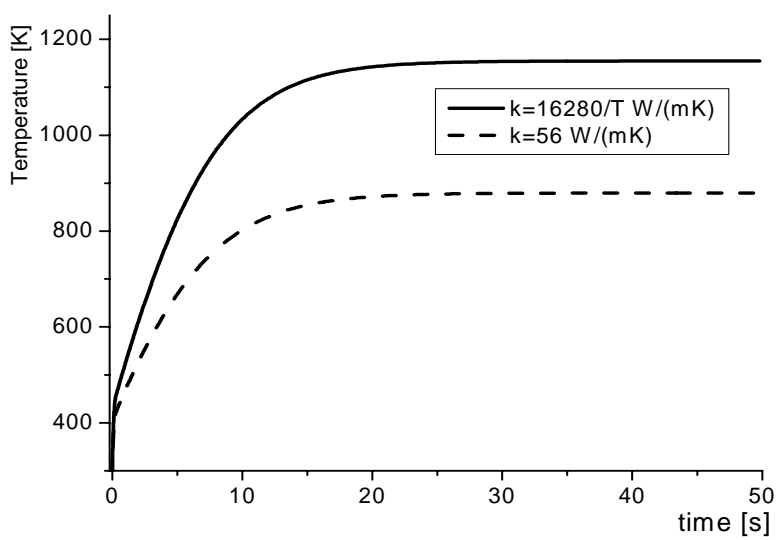

Fig.1 Calculated transient temperatures for different thermal conductivity coefficients.

coefficients. It can be seen that for both the roomtemperature thermal conductivity, $\mathrm{k}=56 \mathrm{~W} / \mathrm{m} \cdot \mathrm{K}$ (broken line), and the temperature dependent conductivity (solid line) calculated temperatures saturate within the first 15 second of the irradiation. For the temperature dependent thermal conductivity, the maximum temperature is $1150 \mathrm{~K}$. This is $300 \mathrm{~K}$ greater than the temperature calculated with the room-temperature coefficient of thermal conductivity. Qualitatively, this difference can be explained by the reduced ability of GaAs to dissipate heat at elevated temperatures, as its thermal conductivity at $1150 \mathrm{~K}$ is $14.2 \mathrm{~W} / \mathrm{m} \cdot \mathrm{K}$, which is about 4 times smaller than this value at room temperature.

Figure $2 \mathrm{a}$ demonstrates that saturation temperatures as well as their temporal behaviors strongly depend on the value of optical absorption $(\alpha)$. For $\alpha=3 \mathrm{~cm}^{-1}$, representing a weakly absorbing GaAs such as undoped GaAs irradiated at room temperature with photons at $1064 \mathrm{~nm}[15,16]$, it would take about $50 \mathrm{~s}$ to reach $367 \mathrm{~K}$. However, for $\alpha \geq 1000 \mathrm{~cm}^{-1}[17]$, the saturation temperature is predicted to be achieved within $15 \mathrm{~s}$ of the onset of irradiation. The maximum temperature in such a case is about $1125 \mathrm{~K}$, and it is expected to increase by only $2 \%$ if calculated for greater values of optical absorption, as shown by the solid line in Fig. 2a.

Figure $2 \mathrm{~b}$ shows transient temperatures in the GaAs wafer, calculated for $\mathrm{k}=16280 / \mathrm{T} \mathrm{W} / \mathrm{m} \cdot \mathrm{K}$, $\alpha=-7492.5+24.985 . \mathrm{T} \mathrm{cm}^{-1}$ and various emissivity coefficients $(\varepsilon=0.4 ; 0.6 ; 0.8 ; 1)$. Assumption of the ideal 

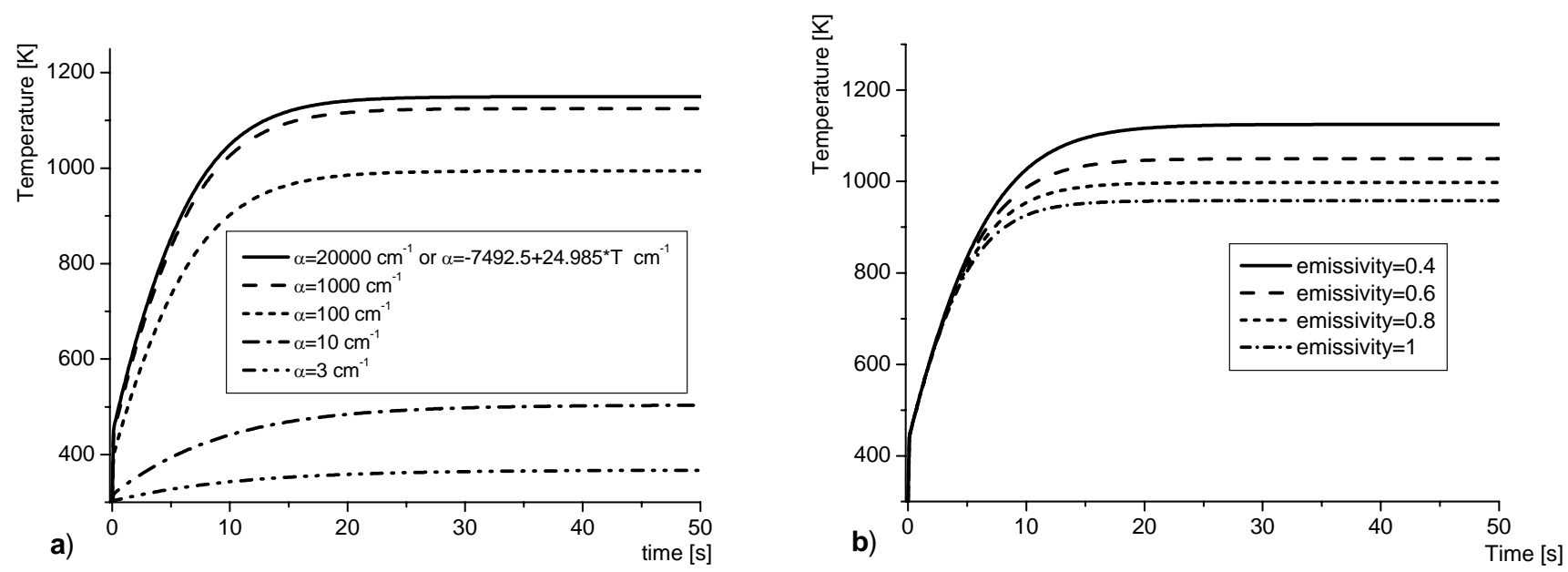

Fig. 2. Calculated transient temperatures in the middle of the laser irradiated spot on GaAs for different optical absorption (a) and emissivity (b) coefficients.

case of the black body surface $(\varepsilon=1)$ results in the underestimated temperature. A difference of $166 \mathrm{~K}$ in the saturation temperature is expected if the surface of GaAs has its emissivity reduced to $\varepsilon=0.4$.

\section{Experimental details}

A continuous wave $(\mathrm{CW}) \mathrm{Nd}$ :YAG laser operating at a wavelength of $\lambda=1064 \mathrm{~nm}$ was used to irradiate GaAs and $\mathrm{Si}$ wafers. The laser spot was $0.7 \mathrm{~mm}$ in diameter. The GaAs wafer used in high-temperature experiments was capped on both sides with a $270 \mathrm{~nm}$ thick layer of $\mathrm{SiO}_{2}$. This cap prevented the wafer from decomposition and it served as an antireflection coating leading to the increased coupling efficiency of the laser radiation to the sample. A schematic diagram of the laser irradiation setup is shown in Figure 3. To minimize heat dissipation by thermal contact the irradiated wafer was supported by 3 quartz rods with needle tips. The GaAs wafer's dimensions were $10 \mathrm{~mm} \times 10 \mathrm{~mm} \times 0.3 \mathrm{~mm}$. The Si wafer was 2 inches in diameter. Temperature measurements were carried out with a fiber optic pyrometer equipped with a $50 \mathrm{~mm}$ focal length lens. This enabled us to collect a signal form the area of about $2 \mathrm{~mm}^{2}$. The pyrometer was capable of acquiring data

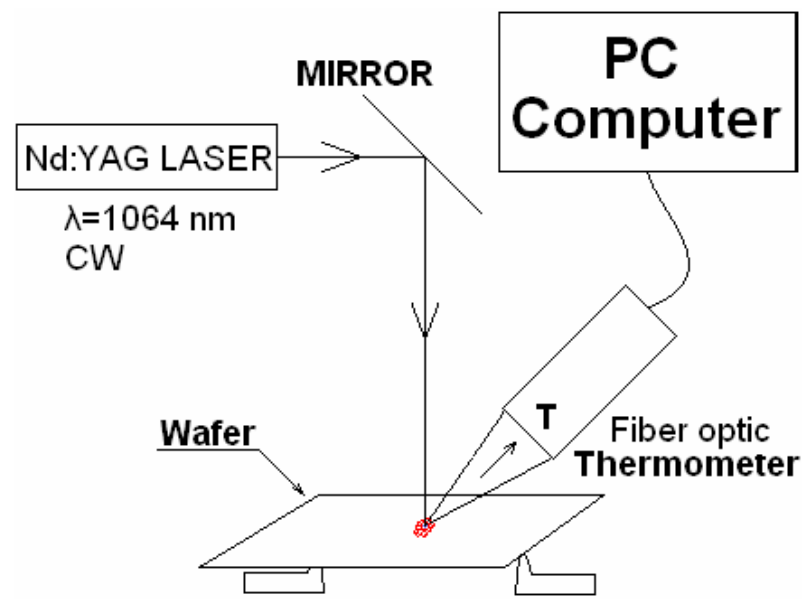

Fig.3 Schematic diagram of the experimental setup used for temperature measurements of Nd:YAG laser irradiated wafers. at the $0.1 \mathrm{~s}$ interval. The minimum temperature that could be monitored with the pyrometer was about $675 \mathrm{~K}$. Irradiation of GaAs was carried out with laser power density of $1 \mathrm{~W} / \mathrm{mm}^{2}$. Optical reflection measurements carried out on GaAs wafers have shown that the reflected power decreased from $34 \%$ for a bare wafer to $10 \%$ for the wafer coated with a $270 \mathrm{~nm}$ thick layer of $\mathrm{SiO}_{2}$.

Details of the irradiation experiment of the $\mathrm{GaAs} / \mathrm{Al}_{0.31} \mathrm{Ga}_{0.69} \mathrm{As}$ multi-quantum-well microstructure have been published elsewhere [2]. Briefly, the microstructure consisted of 32 pairs of QWs (6 nm GaAs) and barrier (35.3 nm $\left.\mathrm{Al}_{0.31} \mathrm{Ga}_{0.69} \mathrm{As}\right)$ material. Each of the QWs was $\delta$-doped with a $9 \times 10^{11} \mathrm{~cm}^{-2} \mathrm{Si}$ spike. Top $(411.8 \mathrm{~nm})$ and bottom $(771.3 \mathrm{~nm})$ GaAs layers were Si doped to $1.5 \times 10^{18} \mathrm{~cm}^{-3}$. The dimensions of the sample were about $14 \mathrm{~mm} \times 6 \mathrm{~mm} \times 0.375 \mathrm{~mm}$.

\section{Discussion of transient temperature behavior}

Figure 4 shows both calculated (dotted line) and measured (broken line) temporal temperature behaviors in the middle of the laser spot irradiating the $\mathrm{GaAs} / \mathrm{Al}_{0.31} \mathrm{Ga}_{0.69} \mathrm{As}$ microstructure. The calculated results have been obtained for the following parameters: $\alpha=-7492.5+24.985 \cdot \mathrm{T} \mathrm{cm}^{-1}, \mathrm{k}=16280 / \mathrm{T} \mathrm{W} / \mathrm{m} \cdot \mathrm{K}, \varepsilon=0.4$ and the laser power of $1 \mathrm{~W} / \mathrm{mm}^{2}$ delivered to a $3-\mathrm{mm}$ diameter spot. A reasonable agreement has been observed between the experimental and calculated data. The maximum temperature of $1100 \mathrm{~K}$ has been achieved within the first $10-15$ seconds of the irradiation. However, it should be pointed out that the quantitative agreement between the measured and calculated maximum temperatures could be coincidental due to the uncertainty of the emissivity coefficient.

We also observed the qualitative agreement between the experimental and calculated data for both $\mathrm{GaAs}$ and $\mathrm{Si}$ wafers irradiated with the laser. This provides the basis for future quantitative description of the LRTA QWI process.

\section{Calculated temperature profiles}

Figures 5 and 6 show calculated both lateral and indepth temperature profiles induced in GaAs wafers by irradiation with 700 and $100 \mu \mathrm{m}$ laser spots for various 


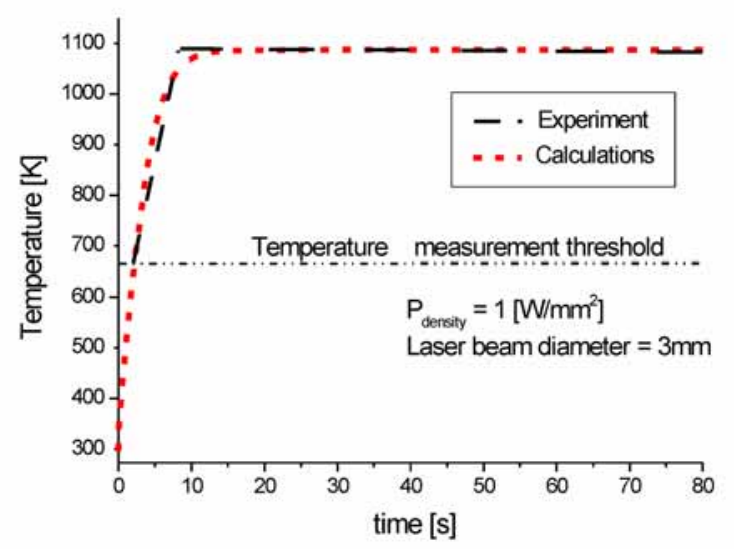

Fig.4 Measured [2] and calculated transient temperatures in $\mathrm{GaAs} / \mathrm{AlGa}_{0.69} \mathrm{Ga}_{0.69}$ As wafer in the middle of the laser irradiated spot.

convection coefficients and different background heating temperatures. The results have been plotted for a steady state temperature distribution, which takes place approximately after $20 \mathrm{~s}$ from initiating the irradiation (see Fig. 4).

The thermal conductivity and optical absorption have been considered as temperature dependent (see Table 1). Also, for each figure, calculations have been carried out for such laser power density that the maximum surface temperature was the same and equal to $1150 \mathrm{~K}$. Note that $\mathrm{h}=0$ corresponds to the irradiation of a wafer in vacuum, while $\mathrm{h}=20$ and $100 \mathrm{~W} / \mathrm{m}^{2} \mathrm{~K}$ qualitatively describes the irradiation at room environment and with forced air cooling, respectively.

Figures $5 \mathrm{a}$ and $6 \mathrm{a}$ show that increased convection requires greater laser beam power densities to achieve the same surface temperature. It can also be seen that increasing thermal convection leads to sharper temperature profiles. This is the result of increased optical absorption and decreased thermal conductivity of GaAs at elevated temperatures. Further narrowing of lateral and in-depth temperature profiles is possible by decreasing the processing laser beam diameter. It can be seen in Fig. 5a that processing with the $100 \mu \mathrm{m}$ laser spot results in a 10-fold narrowing of the high temperature region when compared to processing with the $700 \mu \mathrm{m}$ laser spot. However, processing with the $100 \mu \mathrm{m}$ laser beam at room ambient conditions would require laser beam power density of $136 \mathrm{~W} / \mathrm{mm}^{2}$ if the surface temperature were to be the same. Processing with such power is expected to be damaging to the GaAs surface. Also, increased temperature gradients could lead to thermally induced mechanical stresses in the laser-irradiated wafer. Thus, processing with smaller laser spots requires the additional background heating to reduce both the thermally induced stresses and the chance of damaging the wafer. Figures $5 \mathrm{~b}$ and $6 \mathrm{~b}$ show the calculated lateral and in-depth temperature profiles in GaAs wafers for the $700 \mu \mathrm{m}$ and $100 \mu \mathrm{m}$ laser irradiating spots at room ambient conditions $\left(\mathrm{h}=20 \mathrm{~W} / \mathrm{m}^{2} \mathrm{~K}\right)$ for different background heating temperatures. It can be seen that background heating to $973 \mathrm{~K}$ allows for reducing the laser power density delivered by the $100-\mu \mathrm{m}$ spot to below the surface damage threshold for GaAs (expected to be less than $40 \mathrm{~W} / \mathrm{mm}^{2}$ ). The full width of the transition from 1150 to $1100 \mathrm{~K}$ has increased to $40 \mu \mathrm{m}$, which compares with $20 \mu \mathrm{m}$ for the no-background heating case. However, assuming that this temperature range would be usable for the intermixing process, the width of the LRTA written line of the QWI material is expected to be less than half the width of the writing laser beam. Figure 6 shows the calculated in-depth temperature profiles induced in GaAs wafer for various convection parameters and background temperatures. Convection strongly influences the in-depth laser induced temperature profiles. This is especially evident in the case of processing with the smaller laser beam diameter. It can be seen in Fig. 6a that the enhanced surface cooling $\left(\mathrm{h}=100 \mathrm{~W} / \mathrm{m}^{2} \mathrm{~K}\right)$ results in a rapid decay of the in-depth temperature profile to about $1100 \mathrm{~K}$ at $5 \mu \mathrm{m}$ below the surface. Introduction of background heating to $973 \mathrm{~K}$ relaxes the power density requirement to $27 \mathrm{~W} / \mathrm{mm}^{2}$. This also results in the
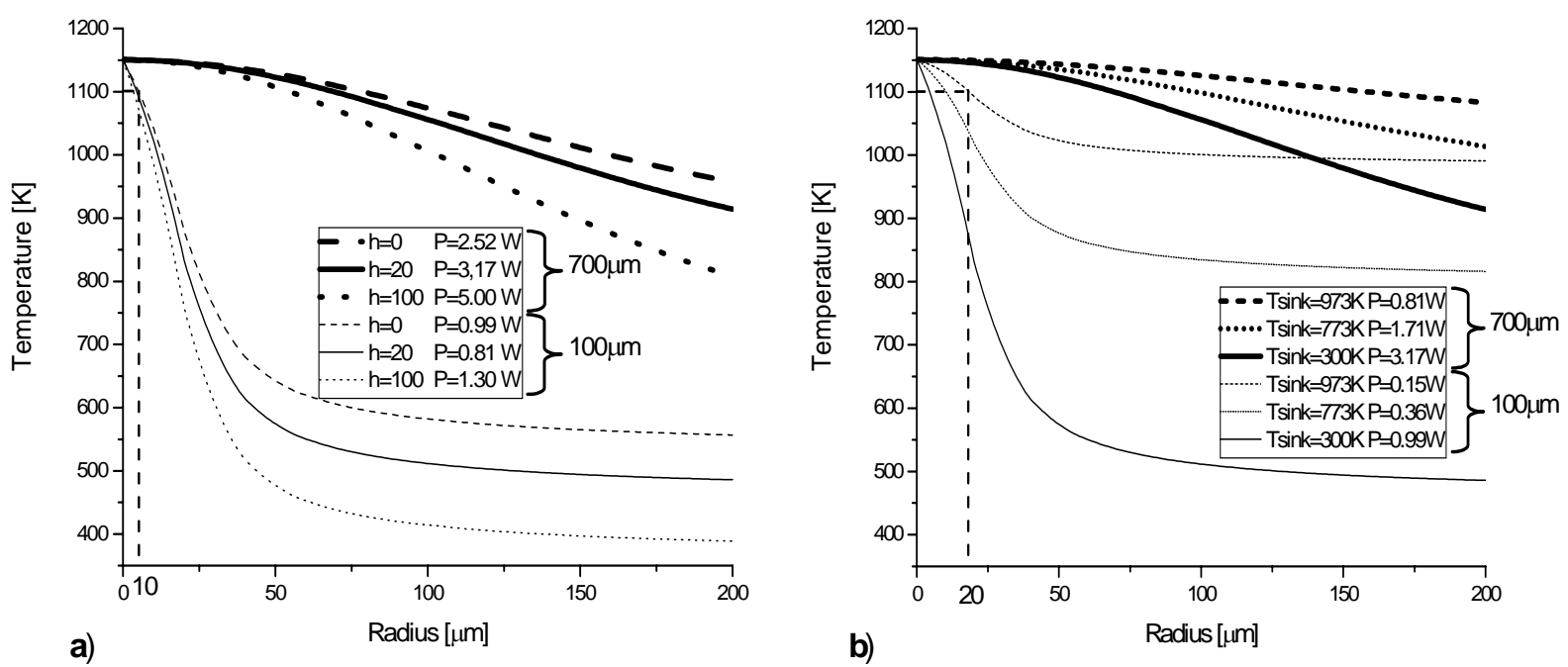

Fig.5 Lateral temperature profiles in GaAs calculated for both $700 \mu \mathrm{m}$ and $100 \mu \mathrm{m}$ laser irradiating spots for different convection conditions (a) and for room ambient conditions $(\mathrm{h}=20)$ at different background temperatures (b). 

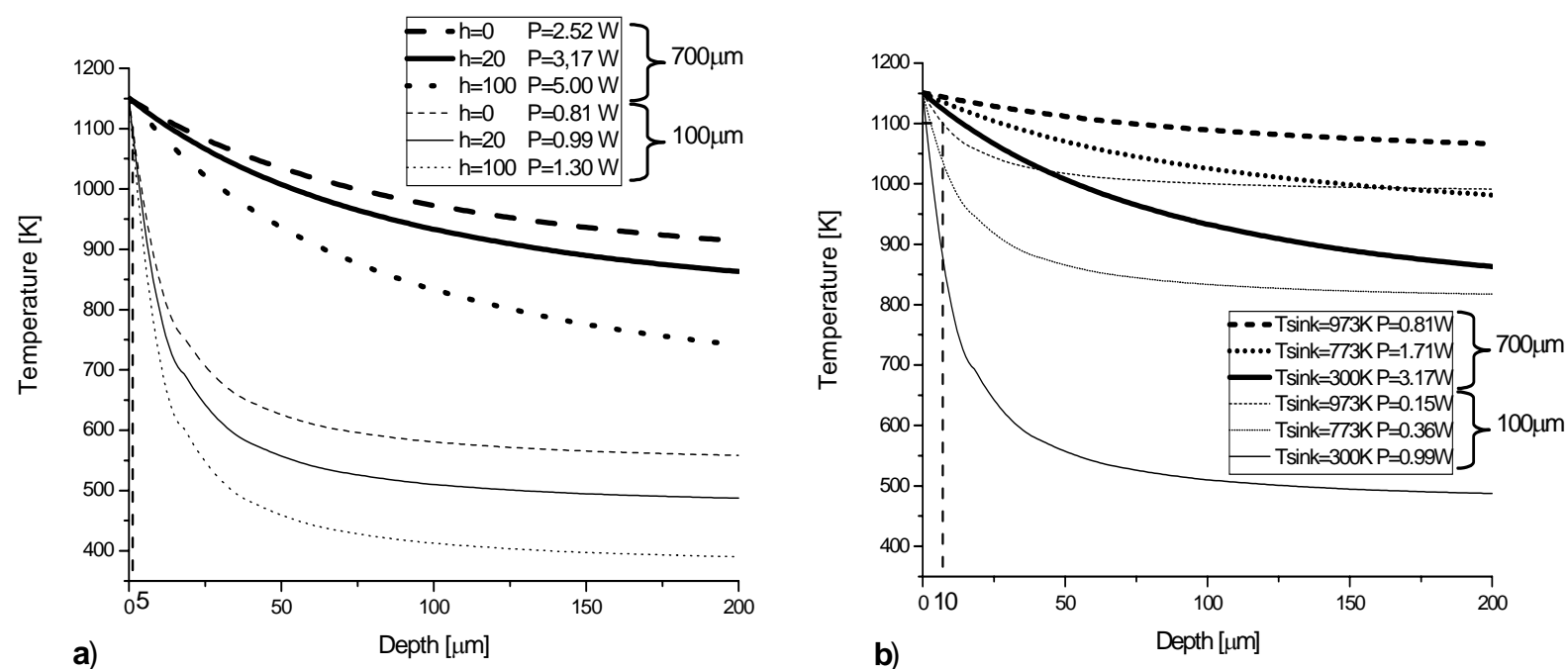

Fig.6 In-depth temperature profiles in GaAs calculated for both $700 \mu \mathrm{m}$ and $100 \mu \mathrm{m}$ laser irradiating spots for different convection conditions (a) and for room ambient conditions $(\mathrm{h}=20)$ at different background temperatures (b).

extension of the region of temperatures greater than $1100 \mathrm{~K}$ to $10 \mu \mathrm{m}$ below the surface (see Fig. $6 \mathrm{~b}$ ).

\section{Conclusions}

We have carried out FEM calculations of temperature profiles in GaAs wafers irradiated with a CW Nd:YAG laser. The influence of both convection and background heating of laser-irradiated samples on the lateral and in-depth temperature gradients has been investigated. The irradiation assisted with forced air cooling makes it possible to generate significantly sharper temperature profiles than those induced by the irradiation of samples in atmospheric ambience or vacuum. However, forced cooling requires greater laser power densities to achieve the same surface temperature. This could result in heating with power densities exceeding the threshold for surface damage. Background heating is necessary to fabricate narrow lines of the QWI material $(\mathrm{T}>1100 \mathrm{~K}$ for GaAs/AlGaAs QW microstructures) in wafers which lateral dimensions are significantly greater than the diameter of the laser spot. This allows for the operation of the laser below the surface damage threshold. For instance, a surface temperature of $1150 \mathrm{~K}$ is achieved during irradiation of a 9-mm-diameter sample with a $100 \mu \mathrm{m}$ laser spot at $\mathrm{P}=27 \mathrm{~W} / \mathrm{mm}^{2}$, if its background temperature is kept at $973 \mathrm{~K}$. The same surface temperature, without background heating, would required $\mathrm{P}=136 \mathrm{~W} / \mathrm{mm}^{2}$, which greatly exceeds the threshold for surface damage for the investigated material system. Our preliminary calculations indicate that about $50 \mu \mathrm{m}$ lines of the bandgap shifted GaAs/AlGaAs material could be written with a $100 \mu \mathrm{m}$ laser spot if the material background temperature were maintained at $973 \mathrm{~K}$.

\section{Acknowledgements}

The funding for this research has been provided by the Natural Sciences and Engineering Research Council of Canada and the Canada Research Chair Program.

\section{References}

1. E. H. Li: "Quantum Well Intermixing for Photonics", (SPIE, Washingon, 1998) Selected Papers.

2. J. J. Dubowski，X. R. Zhang, X. Xu，J. Lefebvre, and Z. Wasilewski: Proc. SPIE, 5339, (2004) p. 93.

3. J. H. Marsh: Semicond. Sci. Technol., 8, (1993) 1136.

4. O. P. Kowalski, C. J. Hamilton, S. D. McDoughall, J. H. Marsh, A. C. Bryce, R. M. De La Rue, B. Vögele, and C. R. Stanley: Appl. Phys. Lett., 72., (1998) 581.

5. N. Holonyak: IEEE Journal of Selected Topics in Quantum Electronics, 4, (1998) 584.

6. P. J. Poole, G. C. Aers, Y. Feng, E. S. Koteles, R. D. Goldberg, and I. V. Mitchell: IEEE Photonics Technology Letters, 8, (1996) 1145.

7. H. Kim, J. W. Park, D. K. Oh, K. R. Oh, S. J. Kim, and I. Choi: Semicond. Sci. Technol., 15, (2000) 1005.

8. J. D. Ralston, A. L. Moretti, R. K. Lain, and F. A. Chambers: Appl. Phys. Lett., 50, (1987) 1817.

9. J. E. Epler, R. D. Burnham, R. L. Thornton, T. L. Paoli, and M. C. Bashaw: Appl. Phys. Lett., 49, (1986) 1447.

10. J. H. Marsh, A. C. Bryce, R. M. De La Rue, C. J. McLean, A. McKee, and G. Lullo: Appl. Surf. Sci., 106, (1996) 326.

11. B. S. Ooi, T. K. Ong, and O. Gunawan: IEEE Journal of Quantum electronics, 40, (2004) 481.

12. R. O. Bell, M. Toulemonde and P. Siffert: Appl. Phys., 19, (1979) 313.

13. O.C. Zienkiewicz and R. L. Taylor "The Finite Element Method", (Butterworth-Heinemann, Oxford, 2000) p.57.

14. W. M. Steen "Laser Material Processing", (SpringerVerlag London Limited, London, 1998) p.193.

15. M. Levinshtein, S. Rumyantsev, and M. Shur: "Handbook series on semiconductor parameters", (World Scientific Publishing Co. Pte. Ltd., Singapore, 2000) p.77.

16. Electronic archive "New Semiconductor Materials. Characteristics and Properties", Ioffe PhysicoTechnical Institute, http://www.ioffe.rssi.ru/sva/nsm

17. S. R. Johnson and T. Tiedje: J. Appl. Phys., 78, (1995) 5609. 
(Received: April 27, 2005, Accepted: August 23, 2005) 